\title{
Genetic Variability and Correlation of Biochemical and Sensory Characteristics of Coffee
}

\author{
Jane Jerono Cheserek ${ }^{1}$, Kahiu Ngugi ${ }^{2}$, James Wanjohi Muthomi ${ }^{2}$, Chrispine Ogutu Omondi ${ }^{3}$ \\ $\&$ Cecelia Wakigondi Kathurima ${ }^{1}$ \\ ${ }^{1}$ Kenya Agricultural and Livestock Research Organization (KALRO), Coffee Research Institute, Ruiru, Kenya \\ 2 Department of Plant Sciences and Crop Protection, Faculty of Agriculture, College of Agriculture and \\ Veterinary Sciences, University of Nairobi, Nairobi, Kenya \\ ${ }^{3}$ Kenya Agricultural and Livestock Research Organization (KALRO), Sugar Research Institute, Kisumu, Kenya \\ Correspondence: Jane Jerono Cheserek, Kenya Agricultural and Livestock Research Organization(KALRO), \\ Coffee Research Institute, P.O. Box 4-00232, Ruiru, Kenya. E-mail: cheserekjerono@gmail.com
}

Received: January 18, 2021

Accepted: December 4, 2021

Online Published: January 15, 2022

doi:10.5539/jas.v14n2p95

URL: https://doi.org/10.5539/jas.v14n2p95

\begin{abstract}
Organoleptic and biochemical attributes in the coffee bean determine the final cup quality of coffee which is a critical factor in the price determination of coffee in the market. The study aimed at determining the genetic variability of the green coffee bean. The trial sites were located at Siaya and Busia counties in Kenya. Nineteen different genotypes were established and included Arabusta coffee hybrids, backcrosses of Arabica to tetraploid Robusta, Arabica coffee, Robusta coffee, and Arabusta coffee. Randomized Complete Block Design with three replications in each site was used in conducting the experiment. The coffee beans were harvested in the year 2018 and extraction and calculation of sucrose, trigonelline, caffeine, and chlorogenic acids was carried using the recommended methods. The cupping procedure involved the use of five judges in assessing the flavor, aroma, balance, overall standard, acidity, body, and aftertaste of the roasted coffee beans. The sensory evaluation used the Specialty Coffee Association (SCA) method. There were significant variations recorded for the traits that were measured. All the traits were highly heritable registering values of $>50 \%$ for heritability whereby, caffeine and oil were highly heritable traits with $90.8 \%$ and $88.9 \%$ respectively. Oil had a high phenotypic coefficient of variation, genotypic variation, and response values when compared to the other traits. All the organoleptic traits were positively correlated with sucrose, trigonelline, and oil but the correlation with caffeine and chlorogenic acids was negative. The genotypic effects contributed largely to the high heritability recorded with a low influence from the environmental factors.
\end{abstract}

Keywords: breeding, genetic variation, quality, selection

\section{Introduction}

Coffee is an important beverage being the second traded commodity after petroleum (Sunarharum et al., 2018; Tolessa et al., 2019). Coffee supports the livelihoods of over 125 million people in the world within the whole value chain (Bunn, 2015). In Kenya, coffee is the fourth most important commodity that contributes greatly to the Gross Domestic Product (GDP) with earnings of about US\$230 million supporting over 700,000 livelihoods (International Coffee Organization, 2019). Kenya prides itself on being among the top producers of the best quality coffee in the world and this is favored by the good environmental conditions which include well-distributed rains, high altitude, red volcanic soils, and processing methods among other factors. The importers and exporters of coffee consider cup quality as a very critical aspect of marketing since it determines the final price. The consumer's preference is also important since it defines the type of coffee that is produced. The quality of coffee; physical quality, liquor quality, and biochemical attributes are dependent on genetics, environmental factors, agricultural practices, and the post-harvesting processing methods (Gichimu et al., 2014; Leroy et al., 2006).

The production of coffee in Kenya, however, has been on the decline over the last 30 years from about 135 metric tons in the 1980s to the current 45 metric tonnes. With climate change, lack of more improved varieties, genetic degradation, and poor agro-processing conditions, the production and quality of coffee are expected to 
decline further if drastic measures are not put in place immediately (Olika et al., 2011; Tariku et al., 2020). There is a need to produce more improved varieties that are of high quality and adapted to different environments in order to cope up with the changing climatic conditions. To achieve this, understanding the genetic variability of the quality traits of coffee beans within the genotypes to be utilized in the development of new varieties is key (Tariku et al., 2020).

Genetic breeding is based on the selection of phenotypic traits that are influenced by environmental factors, additive and non-additive genetic effects (Xu et al., 2017). The additive gene effect contributes largely to high heritability while dominance and epistasis are associated positively with low heritability (Khan et al., 2018). Thus, the phenotypic values are determined by the presence of the genotypic and environmental factors and their interaction. There is limited knowledge on the genetic variability, genetic gain, and heritability of biochemical and organoleptic attributes within the coffee bean. Genetic parameters and heritability indicate the variability existing and this ensures an effective selection of phenotypic traits measured by determining the most important traits depending on their performances (Getachew et al., 2017).

Heritability is key in understanding the degree by which a specific trait is passed on from one generation to the next making the selection process more efficient (Rosmaina et al., 2016). Genetic advance explains the levels of gain achieved from one cycle of selection to the next (Rosmaina et al., 2016). When heritability is combined with genetic gain, it is possible to predict the performance of various quality traits during selection for genetic improvement. This study sought to understand the genetic variability and the relationship between the organoleptic and biochemical traits of coffee genotypes that are being selected for varietal release in Kenya. The genotypes include Arabica coffee, Robusta coffee, and Arabusta coffee hybrids developed for the low altitude regions suited for Robusta production. The study aims to reveal the genetic variability existing with the organoleptic and biochemical traits in aid for selection in breeding for quality.

\section{Materials and Methods}

\subsection{Experimental Materials, Study Site, and Experimental Design}

Nineteen different genotypes including backcrosses of Arabica to tetraploid Robusta, Arabica coffee (Batian and Ruiru 11), Robusta coffee, Congusta, Congensis, and Arabusta coffee were used in the experiment (Table 1). The materials had been earlier selected for yield and resistance to coffee berry disease at Ruiru before establishing them in the new sites. The experiments were carried out in Busia and Siaya counties respectively within the Western region of Kenya. Busia county has an altitude varying from $1241 \mathrm{~m}$ to $1343 \mathrm{~m}$ above sea level. It receives annual rainfall $925 \mathrm{~mm}$ to $1900 \mathrm{~mm}$. The soils are dolerites and andesites. Siaya county has an altitude that ranges from $1,135 \mathrm{~m}$ to $1,500 \mathrm{~m}$ above sea level. The county receives rainfall ranging between $890 \mathrm{~mm}$ and $1,900 \mathrm{~mm}$. The soils found at Siaya are chromic/orthic acrisols and ferrasol (Jaetzold et al., 2009). Randomized Complete Block Design with three replications was used to set up the experiment. The trees were three years old when the cherry was harvested. 
Table 1. Description of materials used during the study

\begin{tabular}{ll}
\hline Code & Pedigree information \\
\hline ARH1 & Hybrid \\
ARH2 & Hybrid \\
ARH3 & Hybrid \\
ARH4 & Hybrid \\
ARH5 & Hybrid \\
ARH6 & Hybrid \\
ARH7 & Hybrid \\
BC01 & Backcross \\
BC02 & Backcross \\
BC03 & Backcross \\
BC04 & Backcross \\
BC05 & Backcross \\
BC06 & Backcross \\
AV1 & CONGUSTA 161 CRAMER \\
AV2 & CONGENSIS 263 CRAMER \\
AV3 & 169, 177, 178 ARABUSTA \\
Robusta & Cultivar \\
Ruiru 11 & Hybrid \\
Batian & Pureline \\
\hline
\end{tabular}

\subsection{Data Collection}

\subsubsection{Sensory Evaluation}

The ripe cherry was harvested from different genotypes and processed using wet processing methods (Gichumu, 2014). The parchment was dried to attain a moisture content of 10.5 to $12 \%$ before being de-husked to get the green beans. The beans were then separated based on sizes using sieves with different measurements to achieve the seven different grades of coffee (AA, AB, PB, C, E, TT, T). The beans graded as AA and AB were roasted using a probate roaster to achieve the medium roast. The roasted beans were then processed for cupping by five judges to determine the quality attributes including flavor, balance, acidity, aroma, preference, aftertaste, and overall standard. The SL 28 variety was used as the standard during the cupping session. The cupping was carried out as per standards provided by Specialty Coffee Association (SCA).

\subsubsection{Biochemical Analyses}

(1) Extraction and Analysis of Caffeine, Trigonelline, and Total Chlorogenic Acids (CGA)

The extraction of these biochemical traits was done using the protocols as provided by CIRAD (2003a) for caffeine and CIRAD (2003b) for trigonelline with slight modification as applied by Kathurima (2013). The modification made was using $0.2 \mathrm{~g}$ of the coffee powder during the analysis. For chlorogenic acids extraction, $0.2 \mathrm{~g}$ of green coffee powder and $40 \mathrm{ml}$ of distilled water was added into a $250 \mathrm{ml}$ Erlenmeyer flask. Refluxing was done, the filtrate recovered and the volume adjusted to the mark with the mobile phase (same as for caffeine and trigonelline). A $0.45 \mu \mathrm{m}$ micro-filter (Chromafil) was used to filter the eluate and analyzed by High-Performance Liquid Chromatography (HPLC) (Knauer) (Kathurima, 2013).

The HPLC system (Knauer) equipped with a Super Co Discovery C-18 column was used to analyse the caffeine and trigonelline whereas the BDS HYPERSIL C-18 column was used for analyzing the chlorogenic acids. The detector used was a Diode Array Detector at three wavelengths, $266 \mathrm{~nm}$ for trigonelline, $278 \mathrm{~nm}$ for caffeine, and $324 \mathrm{~nm}$ for chlorogenic acids. The mobile phase was HPLC grade methanol (PANREAC) 35\%, distilled water $65 \%$, acetic acid (PROLAB) $0.1 \%$, at a flow rate of $1 \mathrm{ml} / \mathrm{min}$ under ambient temperature. Caffeine, trigonelline, and CGA were identified by comparing the retention times of caffeine standard (99\%) (Fischer Scientific), trigonelline standard (Sigma Aldrich), and CGA standard (Acros organics), and calibration equations were used to calculate their concentrations using their peaks (Kathurima, 2013).

\section{(2) Extraction and Analysis of Sucrose}

Sucrose was extracted and analyzed using the method of Osborne and Voogt (1978) which was applied by Kathurima (2013). $0.2 \mathrm{~g}$ of the green coffee powder was added to $100 \mathrm{mls}$ of $96 \%$ ethanol under reflux. Whatman filter paper number 42 was used in filtering the extract after evaporating it to dryness. Sucrose was 
recovered with $10 \mathrm{mls}$ deionized water and $2 \mathrm{mls}$ of the extract mixed thoroughly with 2 mls Diethyl ether (AR) left to settle and the top layer discarded. The HPLC system (Knauer) equipped with a Eurospher 100-5 NH2 column and a refractive index detector was used in analyzing the sucrose concentration within the extract of the sample. The mobile phase was acetonitrile HPLC grade (SCHARLAU) 75\%, and distilled water $25 \%$ at a flow rate of $1 \mathrm{ml} / \mathrm{min}$ under ambient temperature. The retention times of the sucrose standard by the Fischer Scientific and those of the sample peak were used to calculate sucrose concentration by calculating it using a calibration equation (Kathurima, 2013).

\subsection{Statistical Analysis}

The biochemical and sensory data were subjected to Analysis of Variance (ANOVA) using GENSTAT statistical software (Version 2018) and the effects were declared at 5\% significant levels. General Linear Model (GLM) was used (Jansen, 1993).

$$
\mathrm{Y}^{\wedge}=\beta_{0}+\beta_{1} \mathrm{X}_{1}+\beta_{2} \mathrm{X}_{2}+\ldots+\beta_{\mathrm{k}} \mathrm{X}_{\mathrm{k}}+\mathrm{E}_{\mathrm{i}}
$$

where, For each observation $\mathrm{i}=1, \ldots \mathrm{n}$, where, $\mathrm{n}$ is the observations of one dependent variable; $\mathrm{Y}^{\wedge}=\mathrm{j}^{\text {th }}$ observation of the dependent variable; $\mathrm{j}=1,2, \ldots \mathrm{k} ; \mathrm{X}=$ is the observation of the $\mathrm{j}^{\text {th }}$ independent variable; $\beta=$ parameters to be estimated; $\mathrm{E}_{\mathrm{i}}=$ Distributed normal error.

The Correlation between sensory and biochemical traits was computed using the Pearson Correlation Coefficient.

\subsubsection{Genotypic and Phenotypic Variances}

These were estimated as suggested by Baye (2002) as follows,

$$
\text { Genotypic variance }\left(\sigma_{\mathrm{g}}^{2}\right)=(\mathrm{MSg}-\mathrm{MSe}) / \mathrm{r}
$$

where, $\mathrm{MSg}=$ mean square of genotypes, $\mathrm{MSe}=$ Environmental variance (mean square of error), and $\mathrm{r}=$ number of replications.

Phenotypic variance:

$$
\sigma_{\mathrm{p}}^{2}=\sigma_{\mathrm{g}}^{2}+\sigma_{\mathrm{e}}^{2}
$$

where, $\sigma_{\mathrm{g}}^{2}=$ genotypic variance and $\sigma_{\mathrm{e}}^{2}=$ environmental variance $(\mathrm{MSe}=$ mean square of error).

\subsubsection{Phenotypic and Genotypic Coefficient of Variance}

These were calculated based on formulas provided by Singh and Chaudhary (1985) as follows,

$$
\mathrm{PCV}=\left(\sigma_{\mathrm{p}}^{2} / \mathrm{X}\right) \times 100
$$

Where, $\mathrm{PCV}=$ phenotypic coefficient of variation, $\sigma_{\mathrm{p}}^{2}=$ phenotypic variance and $\mathrm{X}=$ mean of the trait.

$$
\mathrm{GCV}=\left(\sigma_{\mathrm{g}}^{2} / \mathrm{X}\right) \times 100
$$

Where, GCV = genotypic coefficient of variation, $\sigma^{2}{ }_{g}=$ genotypic variance and $\mathrm{X}=$ mean of the trait.

\subsubsection{Heritability (Broad-Sense Heritability)}

This was calculated the formula suggested by Falconer (1989) as follows:

$$
\mathrm{h}_{\mathrm{b}}^{2}=\left(\sigma_{\mathrm{g}}^{2} / \sigma_{\mathrm{p}}^{2}\right) \times 100
$$

where, $\sigma_{\mathrm{g}}^{2}=$ genotypic variance; $\sigma_{\mathrm{p}}^{2}=$ phenotypic variance.

\subsubsection{Genetic Advance (GA) Expected and GA as a Percent of the Mean (GAM)}

These genetic parameters were estimated as per Assefa et al. (1999) using a selection intensity of 5\%.

$$
\mathrm{GA}=\mathrm{K} \times \sigma_{\mathrm{p}} \times \mathrm{h}_{\mathrm{b}}^{2}
$$

$$
\text { GA as } \% \text { of the mean }(\mathrm{GAM})=(\mathrm{GA} / \mathrm{X}) \times 100
$$

where, $\mathrm{K}$ is a constant depending on the selection intensity used; $\sigma_{\mathrm{p}}=$ is phenotypic standard deviation and $\mathrm{h}^{2}{ }_{\mathrm{b}}=$ broad sense heritability; $\mathrm{X}=$ mean of the trait being assessed.

\subsubsection{Expected Response to Selection $(\mathrm{Re})$}

This was estimated using the formula provided by (Singh \& Chaudhary, 1985) as follows,

$$
\operatorname{Re}=\mathrm{i} \sqrt{\sigma_{\mathrm{p}}^{2} \cdot \mathrm{h}_{\mathrm{b}}^{2}}
$$

where, $\mathrm{i}=$ selection intensity at $5 \% ; \sigma_{\mathrm{p}}^{2}=$ phenotypic variance for the trait; $\mathrm{h}_{\mathrm{b}}^{2}=$ broad-sense heritability. 


\section{Results}

\subsection{Estimation of Genetic Variability for the Biochemical and Organoleptic Traits}

The ANOVA results indicated a significant difference within the biochemical and organoleptic attributes (Table 2). There were variations in the genotypic and phenotypic variances which were significant on the characters measured for both sensory and biochemical composition indicating that the coffee genotypes varied from each other. On phenotypic variance $\left(\sigma_{p}^{2}\right)$, oil recorded the high values with chlorogenic acids (CGA) following closely then sucrose while trigonelline and body had the lower values. A similar trend was observed for the genotypic variance $\left(\sigma_{g}^{2}\right)$ (Table 3). Oil, CGA, and sucrose had wider mean ranges while the body and trigonelline had the lowest mean range (Table 2). The broad-sense heritability varied within the attributes measured whereby, caffeine showed the highest percentage of heritability followed closely by oil and sucrose whereas body and balance exhibited the lowest percentages of heritability.

Table 2. ANOVA showing the mean squares for biochemical and organoleptic characters of coffee beans

\begin{tabular}{llllll}
\hline Attributes & Replication & MS Genotype & MS Error & MS Environment & MS G $\times$ E \\
\hline CGA & 0.74 & 8.59 & 1.7 & 4.994 & 2.316 \\
Caffeine & 0.002 & 0.81 & 0.079 & $0.38^{*}$ & 0.08098 \\
Oil & 1.56 & 21.01 & 2.52 & $120.4^{* * *}$ & 2.6 \\
Sucrose & 0.27 & 6.79 & 0.86 & $29.4^{* *}$ & 1.32 \\
Trigonelline & 0.056 & 0.088 & 0.03 & $0.94^{* *}$ & $0.06^{*}$ \\
Aroma & 0.59 & 0.35 & 0.09 & $0.73^{* *}$ & 0.122 \\
Flavor & 0.15 & 0.66 & 0.1 & $2.6^{* * *}$ & 0.08 \\
Aftertaste & 0.15 & 0.44 & 0.1 & $0.62^{* * *}$ & 0.09 \\
Acidity & 0.21 & 0.76 & 0.11 & $2.6^{* * *}$ & 0.15 \\
Body & 0.53 & 0.17 & 0.1 & $0.6^{*}$ & 0.09 \\
Balance & 0.2 & 0.32 & 0.15 & $2.4^{* * *}$ & 0.14 \\
Overall & 0.125 & 0.67 & 0.09 & $4.6^{* * *}$ & 0.11 \\
\hline
\end{tabular}

Note. ${ }^{*}, * *$ and $* * * * *$ significant at $0.05, * *$ and $* * *$ highly significant at 0.01 and 0.001 respectively. CGA: chlorogenic acids.

Table 3. Estimates of the phenotypic and genotypic variances for biochemical and organoleptic attributes of coffee

\begin{tabular}{lllllll}
\hline \multirow{2}{*}{ Traits } & \multicolumn{3}{c}{ Mean range } & & \multicolumn{3}{c}{ Components of variance } \\
\cline { 2 - 3 } \cline { 5 - 6 } & Min & Max & & $\sigma_{\mathrm{p}}^{2}$ & $\sigma_{\mathrm{g}}^{2}$ & $\mathrm{H}^{2}(\%)$ \\
\hline CGA & 7.2 & 11.3 & & 9.7 & 8 & 82.5 \\
Caffeine & 1.3 & 2.6 & & 0.9 & 0.8 & 90.8 \\
Oil & 11.2 & 17.8 & & 22.7 & 20.2 & 88.9 \\
Sucrose & 5.4 & 8.8 & & 7.4 & 6.5 & 88.3 \\
Trigonelline & 1 & 1.5 & & 0.1 & 0.1 & 68.2 \\
Aroma & 7.2 & 8 & & 0.4 & 0.3 & 78.7 \\
Flavor & 6.9 & 8 & & 0.7 & 0.6 & 86.5 \\
Aftertaste & 7 & 7.9 & & 0.5 & 0.4 & 80.8 \\
Acidity & 6.9 & 8.1 & & 0.8 & 0.7 & 87 \\
Body & 7.3 & 7.8 & & 0.3 & 0.2 & 60 \\
Balance & 7.2 & 7.9 & & 0.4 & 0.3 & 65.9 \\
Overall & 6.9 & 8.1 & & 0.7 & 0.7 & 87.9 \\
\hline
\end{tabular}

Note. $\overline{\sigma_{\mathrm{p}}^{2}}=$ Phenotypic variance; $\sigma_{\mathrm{g}}^{2}=$ genotypic variance; $\mathrm{H}^{2}$ : Broad sense heritability.

The genetic advance, response to selection, Phenotypic and Genotypic Coefficients of Variance (PCV and GCV) varied amongst the different biochemical and organoleptic attributes measured (Table 3). The oil, CGA, and sucrose were the traits with high PCV values while the body and aroma had the lowest values. With GCV, oil sucrose and CGA recorded the highest values while body and balance recorded the least values. The traits with high values of Genetic Advance (GA) included oil, CGA, and sucrose while trigonelline and body recorded the 
least. The response (Re) varied also amongst the attributes with oil, CGA, and caffeine recording the highest figures while trigonelline and body exhibited the least values (Table 3).

Table 3. Estimates of the phenotypic and genotypic coefficient of variances, genetic gain, and the response of biochemical and organoleptic attributes

\begin{tabular}{llllll}
\hline Traits & PCV $(\%)$ & GCV $(\%)$ & GA $(\mathbf{\%}=\mathbf{5 \%})$ & GA $(\%$ of mean) & Re \\
\hline CGA & 109.29 & 90.15 & 2.61 & 29.27 & 8.19 \\
Caffeine & 48.50 & 44.04 & 0.25 & 14.30 & 2.56 \\
Oil & 157.26 & 139.77 & 6.55 & 45.39 & 12.98 \\
Sucrose & 102.40 & 90.38 & 2.11 & 29.35 & 7.37 \\
Trigonelline & 9.31 & 6.35 & 0.02 & 2.06 & 0.80 \\
Aroma & 5.64 & 4.44 & 0.13 & 12.83 & 1.67 \\
Flavor & 10.16 & 8.79 & 0.25 & 25.41 & 2.31 \\
Aftertaste & 7.14 & 5.77 & 0.17 & 16.67 & 1.87 \\
Acidity & 11.60 & 10.10 & 0.29 & 29.18 & 2.48 \\
Body & 3.32 & 1.99 & 0.06 & 5.76 & 1.12 \\
Balance & 6.01 & 3.96 & 0.11 & 11.45 & 1.56 \\
Overall & 10.14 & 8.91 & 0.26 & 25.74 & 2.33 \\
\hline
\end{tabular}

Note. PCV: phenotypic coefficient of variance; GCV: genotypic coefficient of variance; GA: genetic advance; GAM: percentage means of genetic advance.

\subsection{Genetic Correlation}

The organoleptic traits had positive significant associations with each other (Table 4). Biochemical attributes caffeine and chlorogenic acids showed significant negative relationships with the organoleptic traits while sucrose, oil, and trigonelline exhibited significant positive relationships with the organoleptic traits. Chlorogenic acids and caffeine had a positive significant association with each other while showing a significantly negative relationship with oil, sucrose, and trigonelline (Table 4). The relationship between sucrose, oils, and trigonelline was significantly positive.

Table 4. Correlation between the organoleptic traits and biochemical attributes of coffee genotypes

\begin{tabular}{|c|c|c|c|c|c|c|c|c|c|c|c|c|}
\hline & Acidity & Aftertaste & Aroma & Balance & Body & Flavor & Overall & Caffeine & CGA & Oil & Sucrose & Trigonelline \\
\hline Acidity & - & $0.96^{* * *}$ & $0.84^{* * *}$ & $0.85^{* * *}$ & $0.87^{* * *}$ & $0.96^{* * *}$ & $0.96^{* * *}$ & $-0.56^{*}$ & $-0.47^{*}$ & $0.72^{* * *}$ & $0.74^{* * *}$ & $0.51^{*}$ \\
\hline Aftertaste & & - & $0.82^{* * *}$ & $0.79^{* * *}$ & $0.89^{* *}$ & $0.95^{* * *}$ & $0.93^{* * *}$ & $-0.51^{*}$ & -0.39 & $0.66^{* *}$ & $0.66^{* *}$ & 0.42 \\
\hline Aroma & & & - & $0.66^{* *}$ & $0.71^{* * *}$ & $0.86^{* * *}$ & $0.85^{* * *}$ & $-0.47^{*}$ & $-0.51^{*}$ & $0.62^{* *}$ & $0.56^{*}$ & 0.42 \\
\hline Balance & & & & - & $0.80^{* * *}$ & $0.83^{* * *}$ & $0.88^{* * *}$ & $-0.48^{*}$ & -0.35 & $0.52^{*}$ & $0.63^{* *}$ & 0.43 \\
\hline Body & & & & & - & $0.84^{* * *}$ & $0.91^{* * *}$ & $-0.48^{*}$ & -0.39 & $0.49^{*}$ & $0.60^{* *}$ & 0.23 \\
\hline Flavor & & & & & & - & $0.93^{* * *}$ & $-0.5273^{*}$ & -0.43 & $0.71^{* * *}$ & $0.67^{* *}$ & 0.45 \\
\hline Overall & & & & & & & - & $-0.60^{* *}$ & -0.51 & $0.68^{* *}$ & $0.73^{* * *}$ & 0.36 \\
\hline Caffeine & & & & & & & & - & $0.92^{* * *}$ & $-0.80^{* * *}$ & $-0.81^{* * *}$ & -0.38 \\
\hline CGA & & & & & & & & & - & $-0.78^{* * *}$ & $-0.73^{* * *}$ & -0.41 \\
\hline Oil & & & & & & & & & & - & $0.91^{* * *}$ & $0.59^{*}$ \\
\hline Sucrose & & & & & & & & & & & - & $0.52^{*}$ \\
\hline
\end{tabular}

Note. ${ }^{*}, * *$ and $* * *: *$ significant at $0.05, * *$ and $* * *$ highly significant at 0.01 and 0.001 respectively. CGA: chlorogenic acids.

\section{Discussion}

There were significant differences in both biochemical and organoleptic traits. Oil, CGA, and sucrose had higher mean ranges of 6.6, 4.1, and 3.4 respectively while the body and trigonelline had the lowest mean ranges of 0.5 when compared to other traits. The significant differences within the mean ranges indicate that there is a wide variation in the organoleptic and biochemical performance of the genotypes for the attributes mentioned. This indicates that genetic variability is an important criterion in the selection of high-quality coffee varieties in coffee improvement programs. Similar findings on variations between the biochemical and organoleptic traits have 
been reported by Gichimu et al., 2014, Kathurima et al., 2013 in Kenya and Tessema et al. (2011), Getu (2009), and Olika et al. (2011) in Ethiopia.

Phenotypic and genotypic variances were high within the biochemical attributes except for trigonelline when compared to the organoleptic traits. The phenotypic variances were high for all the traits in comparison to genotypic variances except for trigonelline and overall standard where the values were equal. The results indicate that the genotypic effects contributed largely to trait expression due to the narrow variation between phenotypic and genotypic variances. The heritability for all the traits was high (> 50\%) and the high heritability, indicates that the trait is more stable to the environmental variations which are not multifarious (Nardino et al., 2016). Caffeine and oil were highly heritable traits with $90.8 \%$ and $88.9 \%$ respectively (Olika et al., 2011). High heritability suggests that the genotypic effects have had a greater influence than the environmental factors (Dutamo et al., 2015). Despite the results of this study showing high heritability for all traits measured, Tessema et al. (2011) reported low heritability for sucrose (10\%) while Olika et al. (2011) also reported low heritability for all the organoleptic traits except aroma intensity which had a high heritability value of $64 \%$. The deviations from these results could be attributed to the different genotypes that were assessed and the different environments where the studies took place.

The PCV was high when compared to the GCV for all the characters measured. Oil had the highest PCV and GCV values followed closely by sucrose and CGA, while body and balance had the lowest. PCV and GCV for biochemical traits were high for the biochemical traits when compared to the organoleptic traits except for trigonelline. GCV and PCV values of greater than $20 \%$ are considered to be high, $10-20 \%$ medium, and $<10 \%$ are regarded as low (Rosmaina et al., 2016). Flavor, acidity, and overall standard had the medium PCV values while acidity had medium GCV values. The rest of the traits had lower PCV and GCV values. The variation between the PCV and GCV values was narrow indicating the environmental influence on heritability was low (Getachew et al., 2017). Genetic advance (GA) expressed as the percentage of the mean (GAM) is classified by Falconer and Mackay (1996) to be low when values are less than $10 \%$ is low, $10-20 \%$ medium, and $>20 \%$ as high. GAM varied between the different traits from $2.06 \%$ to $45.39 \%$. Trigonelline/body had low GAM, caffeine after taste, aroma, and balance had medium GAM while the rest of the traits had high GAM. Additive and non-additive gene actions are determined by the GA in expressing the polygenic traits. When the GA is high then there is additive gene action and low GA points to non-additive gene action. For enhanced selection during breeding, it is important to consider the use of both genetic advances and heritability as tools in determining the useful traits that would add gain to the process. CGA, oil, sucrose, flavor, acidity, and overall standard had both high genetic advance and heritability. These traits can be easily inherited from one generation to the next thus improving selection efficiency (Dutamo et al., 2015). Oil had the highest response when compared to the rest of the traits followed by CGA. The response is key in breeding programs in identifying traits that can be easily used during the selection process to increase the accuracy of selection for specific traits (Fritsche-Neto et al., 2012; Nardino et al., 2016).

Organoleptic characters were significantly associated with each other whereby, acidity correlated highly with after taste, flavor, and aroma $(\mathrm{r}=0.96)$. The organoleptic traits also correlated positively with oil, sucrose, and trigonelline and this indicates the increased levels of sucrose, oil, and trigonelline are directly related to high cup quality. The results of the positive correlation between the organoleptic traits agree to those of Gimase et al. (2014), Dessalegn (2005), and Olika et al. (2011). Tessema et al. (2011) reported negative associations between acidity and most of the organoleptic traits but the relationship amongst the rest of the organoleptic traits was positive. CGA and caffeine correlated negatively to the organoleptic traits and the negative relationship imply that its key to select genotypes with lower quantities of caffeine and CGA to improve liquor quality. Gimase et al. (2014) reported a positive association between CGA and the organoleptic qualities and also a negative association between trigonelline and organoleptic traits. The relationship between the CGA and caffeine to oil, sucrose, and trigonelline was negative but the correlation amongst oil, sucrose, and trigonelline was positive. Odeny et al. (2016) reported positive associations between sucrose, oil, and trigonelline from coffee grown under shade in different environments while Gichimu et al. (2014) found a negative association between the caffeine, CGA, and most of the organoleptic traits. The study revealed that selection for genotypes with high oil and sucrose levels together with low caffeine and CGA levels will lead to selection genotypes with improved organoleptic attributes. This is because, CGA and caffeine increase the astringency and bitterness in the cup while oil, sucrose, and trigonelline contribute largely to the flavor and aroma of coffee which in turn increases the cup quality.

From the study, the results indicate that few traits based on heritability and genetic advance findings can be used in selection during breeding. Flavor and aftertaste which had a highly significant association with both 
organoleptic and biochemical traits (oil and sucrose) can be used in determining the liquor quality of the coffee. Oil and CGA which were highly heritable and had higher genetic advance and response values when compared to the rest of biochemical traits need to be utilized during selection for improved coffee genotypes.

\section{Acknowledgements}

We want to acknowledge the Institute Director, Coffee Research Institute, and Director General—Kenya Agricultural and Livestock Research Organization (KALRO), for the financial support that ensured the completion of this project. Our gratitude also goes to the Coffee Breeding department staff for their support to ensure the project was completed on time.

\section{References}

Assefa, K., Ketema, S., Tefera, H., Nguyen, H. T., Blum, A., Ayele, M., ... Kefyalew, T. (1999). Diversity among germplasm lines of the Ethiopian cereal tef (Eragrostis tef (Zucc.) Trotter). Euphytica, 106, 87-97. https://doi.org/10.1023/A:1003582431039

Baye, T. (2002). Genotypic and phenotypic variability in Vernonia galamensis germplasm collected from eastern Ethiopia. Journal of American Science, 139(2), 161-168. https://doi.org/10.1017/S0021859602002459

Bunn, C. (2015). Modeling the climate change impacts on global coffee production (p. 196, Dissertation for the completion of the academic degree Doctor rerumagriculturarum submitted to the Faculty of Life Sciences at Humboldt-Universitätzu Berlin).

Carvalho, I. R., Szareski, V. J., Mambrin, R. B., Ferrari, M., Pelegrin, A. J., da Rosa, T. C., \& de Souza, V. Q. (2018). Biometric models and maize genetic breeding: A review. Australian Journal of Crop Science, 12(11), 1796-1805. https://doi.org/10.21475/ajcs.18.12.11.p792

CIRAD (Centre de Coopération International en Recherche en Agronomique pour le Développement). (2003a). Analysis of caffeine in green coffee beans (Ref: CIR/CP: 069). CIRAD.

CIRAD (Centre de Coopération International en Recherche en Agronomique pour le Développement). (2003b). Determination of trigonelline in green coffee beans (Ref: CIR/CP: 005). CIRAD.

Dessalegn, Y. B. (2005). Assessment of cup quality, morphological, biochemical and molecular diversity of Coffea arabica L. genotypes of Ethiopia ( $\mathrm{hb}$ Thesis, University of Free State, South Africa). https://doi.org/10.1371/journal.pone.0047981

Dutamo, D., Alamerew, S., Eticha, F., \& Assefa, E. (2015). Genetic Variability in Bread Wheat (Triticum aestivum L.) Germplasm for Yield and Yield Traits. Journal of Biology, Agriculture, and Healthcare, 5, 17.

Falconer, D. S. (1989). Introduction to Quantitative Genetics (p. 438). Longman Scientific and Technical, John Wiley and Sons, Inc., New York.

Falconer, D. S., \& Mackay, T. F. C. (1996). Introduction quantitative Genetics (4th ed.). Longmans Green, Harlow, Essex, UK.

Fritsche-Neto, R., Vieira, R. A., Scapim, C. A., Miranda, V. G., \& Rezende, L. M. (2012). Updating the ranking of the coefficients of variation from maize experiments. Acta Scientiarum. Agronomy, 34, 99-101. https://doi.org/10.4025/actasciagron.v34i1.13115

Getachew, W., Sentayehu, A. L., \& Taye, K. (2017). Genetic variability, heritability and genetic advance for quantitative traits in coffee (Coffea arabica L.) accessions in Ethiopia. African Journal of Agricultural Research, 12, 1824-1831. https://doi.org/10.5897/AJAR2016.12059

Getu, B. (2009). Genotype by environment interaction for organoleptic and biochemical composition quality attributes of coffee (Coffea arabica L.) (M.Sc. Thesis, Alemaya University, Ethiopia).

Gichimu, B. M., Gichuru, E. K., Mamati, G. E., \& Nyende, A. B. (2014). Biochemical Composition within Coffea arabica cv. Ruiru 11 and its Relationship with Cup Quality. Journal of Food Research, 3(3), 31-44. https://doi.org/10.5539/jfr.v3n3p31

Gimase, J. M., Thagana, W. T., Kirubi, D. T., Gichuru, E. K., \& Kathurima, C. W. (2014). Beverage quality and biochemical attributes of Arabusta Coffee $(C$. arabica L. x C. Canephora Pierre) and their parental genotypes. African Journal of Food Science, 8(9), 456-464. https://doi.org/10.5897/AJFS2014.1132

ICO (International Coffee Organization). (2019). Country Coffee Profile. International Coffee Council, $124^{\text {th }}$ Session, Kenya. 
Jaetzold, R., Schmidt, H., Hornetz, B., \& Shisanya, D. (2009). Farm management handbook of Kenya, Natural conditions and farm management information, West Kenya. Ministry of Agriculture, Kenya.

Jansen, J. (1993). Generalized linear mixed models \& their application in plant breeding research (PhD Dissertation, Eindhoven Agricultural University, Wageningen).

Khan, M. H., Ahmad, M., Hussain, M., Hassan, M., \& Ali, Q. (2018). Heritability and trait association studies in maize F1 hybrids. International Journal of Biosciences, 12(1), 18-26. http://dx.doi.org/10.12692/ $\mathrm{ijb} / 12.1 .18-26$

Leroy, T., Ribeyre, F., Bertrand, B., Charmetant, P., Dufour, M., Montagnon, C., ... Pot, D. (2006). Genetics of coffee quality. Brazilian Journal of Plant Physiology, 18(1), 229-242. https://doi.org/10.1590/S1677-04202 006000100016

Nardino, M., Baretta, D., Carvalho, I. R., Olivoto, T., Follamann, D. N., Szareski, V. J., ... Souza, V. Q. (2016). Genetic parameters in maize hybrid analysis in different environments. International Journal of Current Research, 8(08), 35552-35556.

Odeny, D. A., Chemining'wa, G. N., Shibairo, S. I., \& Kathurima, C. W. (2016). Biochemical Components of Shaded Coffee under Different Management Levels. Advance Journal of Food Science and Technology, 12(9), 519-526. https://doi.org/10.19026/ajfst.12.3063

Olika, K., Sentayehu, A., Taye, K., \& Weyessa, G. (2011). Organoleptic Characterization of Some Limu Coffee (Coffea arabica L.) Germplasm at Agaro, Southwestern Ethiopia. International Journal of Agricultural Research, 6, 537-549. https://doi.org/10.3923/ijar.2011.537.549

Rosmaina, S., Hasrol, F. Y., \& Juliyanti, Z. (2016). Estimation of variability, heritability and genetic advance among local chili pepper genotypes cultivated in peat lands. Bulgarian Journal of Agricultural Science, 22, 431-436.

Singh, R. K., \& Chaudhary, B. D. (1985). Biometrical Methods in Quantitative Genetic Analysis (p. 300). Kalyani Publishers, New Delhi.

Sunarharum, W. B., Yuwono, S. S., \& Nadhiroh, H. (2018). Effect of different post-harvest processing on the sensory profile of Java Arabica coffee. Advances in Food Science. Sustainable Agriculture and Agroindustrial Engineering, 1(1), 9-13. https://doi.org/10.21776/ub.afssaae.2018.001.01.2

Tariku, A., Ali, H. M., \& Ayano, A. (2020). Genetic variability study of Tepisurroundings Coffeegermplasm accessions (CoffeaarabicaL.) Based on Quantitative Traits in Ethiopia. Global Scientific Journals, 8(1).

Tessema, A., Alamerew, S., Kufa, T., \& Garedew, W. (2011). Variability and Association of Quality and Biochemical Attributes in Some Promising Coffea arabica Germplasm Collections in Southwestern Ethiopia. International Journal of Plant Breeding and Genetics, 5, 302-316. https://oi.org/10.3923/ ijpbg.2011.302.316

Tolessa, K., Duchateau, L., \& Boeckx, P. (2018). Analysis of coffee quality along the coffee value chain in Jimma zone, Ethiopia. African Journal of Agricultural Research, 13(29), 1468-1475. https://doi.org/ 10.5897/AJAR2018.13118

Xu, Y., Li, P., Zou, C., Lu, Y., Xie, C., Zhang, X., ... Olsen, M. S. (2017). Enhancing genetic gain in the era of molecular breeding. Journal of Experimental Botany, 68(11), 2641-2666. https://doi.org/10.1093/jxb/erx135

\section{Copyrights}

Copyright for this article is retained by the author(s), with first publication rights granted to the journal.

This is an open-access article distributed under the terms and conditions of the Creative Commons Attribution license (http://creativecommons.org/licenses/by/4.0/). 